state reported by smokers during the first days of attempted abstinence. Indeed, the time course of altered activity in reward circuits extended beyond the presence of somatic withdrawal symptoms. This suggests that increased reward thresholds are probably more important in relapse into drug use. Perhaps that is why cocaine relapse is so prevalent. Somatic withdrawal signs are not obvious in cocaine withdrawal but similar alterations in reward threshold are observed ${ }^{4}$. With these new findings, we must accept that alterations in activity of the brain reward system are not tightly tied to the profound acute effects of drugs on subjective experience or motor activation. Something more subtle must be taking place.

Obvious questions raised by this important discovery are: how does the dopamine reward pathway change to produce nicotine withdrawal and, is it altered in the same manner during opioid, ethanol, and cocaine withdrawal? If it is, then we will have to reformulate basic concepts regarding the neurobiology of addiction and withdrawal ${ }^{5,6}$. The last few years have seen the identification of several important cellular and molecular alterations in animal models of addiction and withdrawal, particularly within the brain dopamine reward system ${ }^{7}$. Nicotine has the potential to produce such adaptations by virtue of the fact that stimulation of nicotinic acetylcholine receptors on both dopamine cell bodies in the midbrain and their axon terminals in the nucleus accumbens enhance dopamine release ${ }^{8,9}$. Chronic nicotine administration causes enigmatic increases in nicotinic acetylcholine receptor expression apparently because the receptors are dramatically desensitized ${ }^{10}$.

How are these adaptations then incorporated into reward behavior? Only time will tell. The important point for now is that relatively weak psychoactive agents such as nicotine, when used chronically, can change activity of brain reward pathways in a manner that appears indistinguishable from that of other major drugs of abuse. These provocative findings are certain to fuel the maelstrom of controversy encircling issues of tobacco use. The publication of these results, 24 hours before the announcement of the US\$6.6 billion out-of-court settlement between the U.S. tobacco industry and the State of Minnesota, is more bad news for the tobacco companies as they fight for survival.
1. Epping-Jordan, M.P., Watkins, S.S., Koob, G. \& Markou, A. Dramatic decreases in brain reward function during nicotine withdrawal. Nature 393, 76-79 (1998).

2. Olds, \}. \& Milner, P. Positive reinforcement produced by electrical stimulation of septal area and other regions of the brain. J. Comp. Physiol. Psychol. 47, 419-427 (1954).

3. Wise, R.A. Addictive drugs and brain stimulation reward. Annu. Rev. Neurosci. 19, 319-340 (1996).

4. Markou, A. \& Koob, G.F. Postcocaine anhedonia: an animal model of cocaine withdrawal. Neuropsychopharmacology 4, 17-26 (1991).

5. Robinson, T.E. \& Berridge, K.C. The neural basis of drug craving: an incentive-sensitization theory of addiction. Brain Res. Rev. 18, 247-291 (1993)

6. Wise, R.A. \& Bozarth, M.A. A psychomotor stimulant theory of addiction. Psychol. Rev. 94, 469-492 (1987).

7. Self, D.W. \& Nestler, E.J. Molecular mechanisms of drug reinforcement and addiction. Annu. Rev. Neurosci. 18, 463-495 (1995).

8. Corrigall, W.A., Franklin, K.B., Coen, K.M. \& Clarke, P.B.S. The mesolimbic dopaminergic system is implicated in the reinforcing effects of nicotine. Psychopharmacology 107, 285-289 (1992).

9. Wonnacott, S. Presynaptic nicotinic ACh receptors. Trends Neurosci. 20, 92-98 (1997).

10. Marks, M.I., Burch, J.B. \& Collins, A.C. Effects of chronic nicotine infusion on tolerance development and cholinergic receptors. J. Pharmacol. Exp. Ther. 226, 806-816 (1983).

Department of Cellular and Molecular

Pharmacology

Finch University of Health Sciences/The Chicago Medical School

North Chicago, Illinois 60064-3095, USA

email:whitef@mis.finchcms.edu

\title{
Playing with dopamine release
}

According to Paul Grasby and colleagues (Imperial College School of Medicine, London) in their recent Nature paper, playing a video game stimulates dopamine release in a brain region involved in reward pathways and motor control. As subjects navigated a tank through enemy bunkers, positron emission tomography was used to monitor displacement of a tracer from D2 dopamine receptors by newly released dopamine (see figure). Neurotransmitter release correlated with success in the game for individual subjects, who were paid seven pounds (around ten dollars) for each level completed. This is the first measurement of neurotransmitter release during a behavioral task in humans.

The tracer, $\left[{ }^{11} \mathrm{C}\right]$ raclopride, bound strongly in the striatum (left panel; scale goes from blue, low binding, to red, high binding), which has a high concentration of D2 receptors, as subjects watched a blank screen. During the video game, raclopride binding in this region was reduced significantly, particularly in the ventral striatum (right panel). Researchers infer that playing the game increased the release of synaptic dopamine, reducing the number of receptors available

\section{IMAGE UNAVAILABLE FOR COPYRIGHT REASONS}

to bind the tracer. This technique has very slow time resolution, integrating dopamine release over tens of minutes.

The researchers chose the video game task to maximize the odds of producing a measurable signal, said Grasby. Although raclopride had been used to measure dopamine release in response to amphetamine use in humans, no one knew whether behaviorally induced release would be within the tracer's sensitivity. Playing the game combined several elements known to produce striatal dopamine release in animals: novelty, sensorimotor learning and anticipation of reward. Further experiments will be needed to separate out these elements. For example, if anticipation of reward is critical for activating neurons in this task, then dopamine release might not correlate with performance if subjects are paid the same amount regardless of their success at the game.

Although there is an intriguing parallel between video games and addictive drugs in that both increase dopamine release in the ventral striatum (nucleus accumbens), Grasby emphasizes that his subjects were normal volunteers, not addicts, and that the study was not designed to address dopamine's role in addiction (see above News \& Views). Indeed striatal dopamine projections have also been implicated in the motor disability characteristic of Parkinson's disease and in the positive symptoms of schizophrenia. Grasby, who is a psychiatrist, next plans to turn this technique to exploring how dopamine release correlates with particular symptoms of schizophrenia and depression. Researchers are also seeking tracers that can detect release of other neurotransmitters in humans, but visualizing neurotransmitter release seems to require a poorly understood combination of tracer properties and synaptic properties, so this may prove difficult.

Sandra Aamodt, Nature Neuroscience 